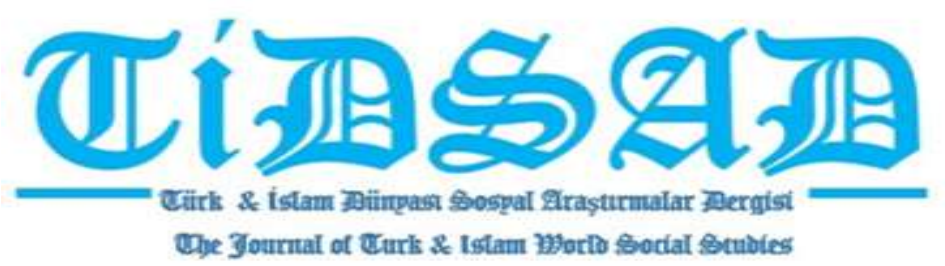

Yıl: 6, Sayı: 23, Aralık 2019, s. 115-122

Öğr. Gör. Ali BíRVURAL

Mustafa Kemal Üniversitesi İktisat-Kamu Yönetimi-Emlak ve Emlak Yönetimi, a.birvural@gmail.com

\title{
OSMANLI DEVLETI'NDE 1854-1874 BORÇLANMALARINA GENEL BİR BAKIŞ ve MOROTORYUM
}

\section{Özet}

Osmanlı Devleti son iki yüz yılını modernleşme çabalarında geçirmiştir; Üretim tüketimi karşılayamamış ve sürekli toprağı kaybederek, savaş maliyeti ve tazminatlar dayanılmaz hale gelmiş ve 1854 'ten beri aldığı dış borçlarını ödeyememiştir. İlk dış borç 1854 yılında Kırım Savaşı nedeniyle alınmıştır. 1874 yılına gelindiğinde 23 ayrı şekilde alınan dış borç 239.000.000 lira iken sadece 127.000.000 lira hükümetin eline geçmiştir. 1865 senesine dek, dış borçların senelik geri ödemesi ancak yeni dıș borçlarla yapılabiliyordu. Bu sonucun ana nedeni, borçlanmaların üretim alanlarında kullanılması yerine dış borcun cari harcamalara tahsis edilmesi olmuştur.

Bütçe gelirleri 1875 y1lına kadar 25 milyon pound olmasına rağmen, zorunlu dış borç 12 milyon pound ve dalgalı borçlar 17 milyon pound idi. Başka bir deyişle, 1875'te Osmanlı Devleti'nin kazandığı gelirler, o yıl borçlarını ödemek için yetersizdi ve 5 milyon sterlinlik borç ödenememiştir. Ancak, hükümetin bütün gelirlerini borçlara tahsis etmesi ve devletin hayatta kalması için cari harcamaları ödemesi mümkün değildir. Kısacası, Osmanlı devleti mali açıdan çökmüş ve morotoryum ilan etmiştir. Bu süreç devletin iktisadi bağımsızlığını kazandığı Cumhuriyet dönemine kadar sürmüştür.

\section{OVERVIEW OF THE 1854-1874 DEBT IN THE OTTOMAN STATE AND MOROTORY}

\footnotetext{
Abstract

The Ottoman State has spent the last two hundred years of modernization; Production was unable to meet consumption, and by constantly losing land, the
} 
cost of war and compensation became unbearable and could not repay its foreign debt since 1854. The first external debt was received in 1854 due to the Crimean War. In 1874, 23 separate foreign debt received 239 million pounds, but only 127 million pounds were received by the government. Until 1865, the annual repayment of foreign debts could only be made with new foreign debts. The main reason for this result was that external debt was allocated to current expenditures instead of using borrowings in production areas.

Although budget revenues were $£ 25$ million by 1875 , compulsory external debt was $£ 12$ million and floating loans were $£ 17$ million. In other words, the income earned by the Ottoman Empire in 1875 was insufficient to repay its debts that year and could not be paid $£ 5$ million. However, it is not able for the state to allocate all its revenues to debts and to pay current expenditures for the survival of the state. In short, the Ottoman state has collapsed financially and declared a morotorium. This process continued until the Republican period when the state gained its economic independence.

Keywords: Borrowing, Foreign Debt, Morotorium, Interest.

\section{GíRİș}

Rusya'nın Akdeniz ticaretine hakim olmasından korkan İngiltere ve Fransa'nın etkisiyle hareketlenen Kırım Savaşı Osmanlı finansmanını oldukça sarsmıştır. 24 Ağustos 1854'te, Osmanlı yöneticileri, İngiltere ve Fransa'nın Osmanlı İmparatorluğu'na borç verme önerilerini kabul ettiler. Böylece dış borçlanma dönemi Osmanlı Devleti'nin mali tarihinde ilk kez başlamıştır. İkinci anlaşma 27 Haziran 1855 'te, kredinin savaş maliyetini karşılamadığ 1 için kabul edildi. Suriye, Mısır ve İzmir gümrük kaynakları bu borçlar için bir teminat olarak rehin edildi.

Osmanlı yöneticileri açısından diş borçlanma alışkanlık haline gelmiş ve 1854 ve 1874 arasında, onbeş dış borç sözleşmesi imzalanmıştır. Devletin ana para olarak 238.773.272 lirayı borç almasına rağmen, düşük fiyatlarla bono satışı ve komisyon maliyetleri nedeniyle 127.122.220 lira elde edilmiş ve bu süreçte yalnızca 1855 tahvilleri gerçek değerinden yükseğe satıldığından elde edilen tutar pozitif olmuştur. Bu süreçteki dış borcun yalnızca\% 7,8'i Balkan demiryolu hattına harcanmış diğer borçlanmalar bütçe açıklarını karşılamak, iç ve dış borcu ödemek ve eski kağıt ve bakır madeni paraları kaldırmak için kullanılmıştır. Her borçlanma sonucunda hükümetin mevcut gelir kaynaklarını teminat olarak bırakması ülkeyi zor duruma sokmuştur.

\section{1854 Senesi Borçlanması}

Kırım Harbi’nin maliyetlerini sağlamak için, Osmanlı İmparatorluğu tarafindan alınan ilk dış kredi sözleşmesidir. Sultan Abdülmecit, 1854'teki fermanı ile yurtdışından 3.000.000 sterlin borç alınmıştır. 
Borç sözleşmesi Osmanlı ile İngiltere ile bilikte değil, Osmanlı ile Londra bankacılarından Palmer, Dent ve bunun Paris'teki şubesi, Goldsmith ile imzalanmıştır. Sözleşme uyarınca, faiz oran1\% 6, ödeme oranı\% 1 ve ihraç fiyatı\% 80'dir. ( Tuncel ve Yıldırım, 2014, 7) Kırım Savaş1 patlak verdiğinde imparatorluk borçlanmak için Avrupa'nın resmi baskısına artık dayanamıyordu.. Devlet, ekonominin üretim kapasitesini artırmak ve borçlarını zorlanmadan ödemek için borç aldığı parayla yatırım yapamıyordu. İmaparatorluk, ilerideki gelirlerinin o anki gelirlerinden daha yüksek olacağını hayal ediyordu. Merkezi bürokrasi, ayanların ve yerel eşrafların gücünü kırmak ve geleneksel siyasi meşruiyetini ve ekonomik fazlalığı kontrol etmesini sağlamak için Avrupa'dan kredi alındı. (Kıray, 2010, 84)

\section{1855 Senesi Borçlanması}

Osmanlı İmparatorluğu'na Kırım Savaşı'nın maliyeti 11.200.000 İngiltere Lirası'nı bulmuştur. Savaş esnasında, devlet bütçesi açığı ise 5.800.000 İngiliz lirasına ulaştı̆̆ında, 1854'deki borçlanma Kırım Savaşı'nın maliyetini karşılamak için yeterli olmadığından, yeni bir borç almak zorunluydu. \% 4 faiz oranı olan bu borcun ardından hazineye 5,650.000 Osmanlı altını sağlanmıştır. Borçlara karşılık 1854'ün Mısır vergi gelirleri, geri kalanı ile Suriye ve İzmir'in gümrük resimleri karşılık gösterilmiştir. ( Tuncel ve Yıldırım, 2014, 8)

\section{1858 Senesi Borçlanması}

Osmanlı İmparatorluğu'nun Kırım Harbi'nin maliyetlerini karşılamak için tedavüle sürdügü, bir cins devletin iç borç belgesi tipinde bulunan ve bununla birlikte para şeklinde bulunan kaimelerin yenilenmesi sebebiyle yapılan borçlanma tipidir. 5.000.000 İngiliz sterlini bedelindeki bu krediye tekrar Londra'da bulunan Palmer, Dent ve ortakları aracı olmuştur. Anlaşma şartlarında faiz sınırı \% 6, ödeme bedeli \%1 düzeyindeki krediye karşın, İstanbul'un gümrük kaynakları ve okturva resminin bir bölümü garanti edilmiştir. ( Tuncel ve Yıldırım, 2014, 8)

\section{1860 Senesi Borçlanması}

1860 senesine varıldığında Osmanlı İmparatorluğu'nun acilen karşılaması gereken diş ve iç borç meblağı altın 10.000.000 liraya varmışır.. Bu meblağın 900.000 lira kadarı daha eskiden sağlanan borçların zamanı gelen taksitleri, diğer bölümü ise Osmanlı'nın yerli sarraflardan sağladığı kısa vadeli borçlardan oluşmaktaydı. Bu tutarın ödenebilmesi için yeniden kredi aramaya giren hükümet, kredi bulma gücünü kaybetmesi sebebiyle zamanın bilinen kreditörlerinden de olumsuz yanit alınca, bilinmeyen bir banker olan Mires ile bir kredi sözleşmesi yapmıştır. Sözleşme koşullarına göre, borçlanmanın toplam tutarı 17.543.860 Osmanlı Lirası, faiz bedeli $\% 6$, ödeme bedeli $\% 0.84$ ve ihraç fiyatı $\% 53.73$ düzeyinde hesaplanmıştır. Osmanlı İmparatorluğu'nun lehine kalacak net tutar ise, 9.429.825 Osmanlı Lirası'dır. Mires'in batması sebebiyle başarısız olan bu kredide tam olarak verilen tahvillerin kağıt üzeri değerleri 2.233.794 Osmanlı Lirası ve İmparatorluğun elinde kalan tutar ise 1.393.121 Osmanlı Lirası gibi düşük bir orandır. (Kıray, 2010, 85)

\section{1862 Senesi Borçlanması}

1858 borçlanması mevcut kaimelerin piyasaların piyasadan çıkartılması için yeterli olmadı̆̆ından, Osmanlı İmparatorluğu yeni bir kredi almak durumunda kalmıştır. Kaimenin çekilme hedefine göre, her kaime \%40'1 bozulmamış para ile ödenecek ve geride kalanına daha 
uzun vadeli tahviller sağlanacaktır. Kredi anlaşması Devaux ve Londra'daki diğer ortaklarla imzalanmıştır. Sözleşme şartlarına göre, 200.000.000 Frank olan kredinin ana faizi \%6, ödeme tutarı $\% 2$ ve ihraç tutarı $\% 68$ olarak belirlendi. Mevcut krediye karşlık tütün, tuz, damga ve temettü gelirleri verilecektir. (Kıray, 2010, 207)

\section{1863 Senesi Borçlanması}

1863 senesine varıldığında Osmanlı İmparatorluğu'nun mali açıdan iki ciddi problemi bulunmaktadır. İlki Galata sarraflarına olan meblağı yüksek borçlar, ikincisi ise 5'lik ve 6'lık şeklinde isimlendirilen ve bedeli oldukça azalmış olan bakır madeni paralardır. Osmanlı İmparatorluğu bu sebeple, yeni oluşturulan Osmanlı Bankası vasıtası ile yeni bir kredi sözleşmesi imzalamıştır.

Osmanlı Bankası ile anlaşılan sözleşmeye göre kullanılacak kredi tutarı 200.000 .000 frank, faiz tutar1 \%6, ödeme bedeli \%2, ihraç tutar1 150.000.000 için \%72, kalan 50.000.000 frank'a \%68 olarak hesaplanmıştır. Borç bedeline karşın, Bursa ve Edirne'nin ham ipek öşürü, İzmir, Karesi ve Midilli'nin zeytin öşürü, bazı eyaletlerin gümrük gelirleri ile 1860 ve 1862 yılında alınan kredilerin artısı karşı1ık gösterilmiştir.

\section{1865 Senesi Borçlanması}

Kendi olanakları ile süresi dolan dış kredilerin anapara ve faiz ödemelerini karşılayamayan Osmanlı İmparatorluğu, yeni bir kredi anlaşmasına gitmek durumunda bulunmuştur. 1865'te varılan bu sözleşmenin aktörleri, Osmanlı İmparatorluğu ile Osmanlı Bankası, Paris’teki Societe General ve Credit Mobilier'dir. Sözleşmeye göre kullanılacak kredinin tutarı 150.000.000 frank, faiz bedeli \%6, ödeme tutarı \%2,24, ihraç tutarı ise 500 franklık her tahvil için 330 frank hesaplanmıştır. Bu krediye ağnam resmi ile Ergani Bakır Madeni kazançları verilmiştir.( Kıray, 2010, 207)

\section{1865 I. Tertip Genel Borçları}

Osmanlı İmparatorluğu, Galata bankerlerinden alınan kredilere karşılık "Esham-1 Cedide", "konsolit", "esham-1 mümtaze" veya "sergi ve hazine tahvili" olarak isimlendirilen iç borçlanma poliçeleri çıkartılmıştır. 1865 kredisi, iç borçların dış borçlara dönüştürülmesi amacıyla imzalanmıştır. Finanaz ve General Credit sözleşmesine göre kredilendirilen tutar 40.000.000 altın Osmanlı lirası karşılığı olup; devlette kalan net tutar 20.000.000 altın Osmanlı lirasıdır.

Hiçbir karşıllı̆ıı verilmediği bu kredinin ihraç bedeli \%50, faizi oranı \%5 olarak hesaplanmıştır. (Kalabak, 2014, 315)

\section{1869 Senesi Borçlanması}

1869 senesine varıldığında Osmanlı İmparatorluğu'nun 1869-1870 gerçekleşen bütçesi 3.000.000 lira eksik vermiş ve ödenmesi zorunlu kısa vadeli kredi tutarı da 5.000.000 liraya varmıştır. Bununla beraber, 1866 senesinde meydana gelen Girit isyanının sona erdirilmesi de Osmanlı İmparatorluğu'na yüksek maliyetlere sebep olmuştur.

Abdülaziz Han'ın Fransa gezisi sebebiyle ülkeler arası ilerleyen ilişkiler, borç sözleşmesinin Comptoir d'Escompte ile imzalanmasına sebep olmuştur. Sözleşmeye göre alınan borç tutarı 555.555.000 frank tutarında olup; ihraç rakam1 \%54, hedef faiz tutarı \%6, ödeme bedeli $\% 1$ 
hesaplanmıştır. Borca karşın Konya, Menteşe, Halep, Adalar Denizi, Adana, Suriye, Trabzon, Yanya, Bosna, Aydın, aşarlarının bir kısmı ile Bağdat gelirlerinin bir kısmı verilmiştir. (Kalabak, 2014, 315)

\section{1870 Senesi Borçlanması}

$\mathrm{Bu}$ kredi ile bir tanesi İstanbul- Belgrat aralığında, başkası ise Selanik'ten Avusturya'ya hududuna kadar olarak $2.000 \mathrm{~km}$ 'lik iki ana demiryolunun inşası hedeflenmiştir. Hattın yapılması için lazım gelen imtiyaz Belçika bankerlerinden Baron Hirsch'e bırakılmıştır.

Baron Hirsh'in yaptığı ikramiye verilen kredi planına göre sağlanacak borcun meblağ 34.848.001 altın Osmanlı lirası, faiz yüzdesi $\% 3$ ve ihraç tutarı ise $\% 32,125$ olarak hesaplanmıştır. Lots-Türk adıyla isimlendirilen bu kredi ile Osmanlı İmparatorluğu'na 11.194.820 altın Osmanlı lirası kalmıştır. Krediye karşın yine Mısır vergisi bırakılmıştır.

\section{1871 Senesi Borçlanması}

1871 senesi Ocak ayına varıldığında Osmanlı İmparatorluğu'nun süresi biten ancak karşılanmayan dış kaynaklı borç meblağı 12.000.000'a varmıştır. 1862, 1863 ve 1865 senelerinden kalan bu borçların tamamının ödenmesi, Londra'da bulunan bir kısım kredi kuruluşlarının $\% 15$ 'den düşük bulunmayan yüksek bir faiz tutarıla avanslandırmalarıyla gerçekleşmiştir. Lakin kısa bir süre sonra, aynı dert yeniden meydana gelmiştir. Londra'da bulunan Louis Cohen and Sons ve Dent Palmer ve Ortakları'nın ait olduğu Credit Generale Otoman ile varılan kredi sözleşmesine göre, 6.270.000 Osmanlı lirası kredinin ana faizi \%6, ödeme tutarı \%1, ihracat fiyatı ise \%73 olarak hesaplanmıştır. Bu kredi ile Osmanlı İmparatorluğu'nun eline altın 4.577.100 Osmanlı lirası kalmıştır.

\section{1872 Senesi Borçlanması}

Dış kredilerin 1872'de hesaplanan itibari değerlerinin ödenmesi, Bank Avusturya -Osmanlı ve Osmanlı Bankası'nın çıkarttığı avanslarla sağlanmıştır.

Ancak verilen bu avansların karşılanması için yeni kredi mecburi hale gelmiştir. Bu bankalarla varılan sözleşmeye göre, devletin 278.155.000 frank tutarında çıartacağı hazine bonoları, bu kurumlarca \%98,5 ihraç tutarıly alacak ve faizi net $\% 9$ hesaplanacaktır. Krediye karşın bu kez Edirne, Selanik ve Tuna eyaletlerinin kaynakları ile Anadolu'dan gelen ağnam resmi karşılık bırakılmıştır.

\section{1873 2. Tertip Borçları}

Devlet, 1872 hazine bonolarınıni vaktinde karşılayamayacağını idrak edince, 1873 yılında çıkarttı̆̆ bir kanunla, “1873 2. Tertip Genel Borçları” bonoları adıyla \%5 faizli 22.252.400 liralık tahvil bastırmıştır.

1872 y1lı hazine tahvillerinin 6.306 .000 sterlin mebalğındaki bölümü genel borç tahvillerine karşı1ık alınmış olup, diğer bölümü ise 4.820 .200 sterlin bedelindedir. Kredinin ihraç oranı $\% 98,5$, piyasa rayici \%84, faiz yüzdesi \%9 hesaplanmıştır. (Kıray, 2010, 210) 


\section{1873 Senesi Borçlanması}

1873 tarihinde Osmanlı İmparatorluğu ve Credit Mobilier ve Credit General kuruluşları arasında imzalanan 694.444.500 franklık kredi sözleşmesine göre kredinin faiz oranı \%6 ve ödeme tutarı \%1 olarak hesaplanmıştır. Bu sözleşme ile imparatorluğun hazinesine 374.777 .830 frank gelmiştir. Krediye karşılık bu sefer, Ankara ve Tuna bölgelerinin aşar vergisi, Anadolu ağnamı ve tütün rejisinin gelirlerinin fazlasının bir kısmı bırakılmıştır.

\section{1874 3. Tertip Genel Borçlanması}

1874 senesine varıldığında zamanı gelen taksitler tekrar kapatılamamıştır. Yerli bankalardan sağlanan 75.000.000 frank ve Fransa'da Osmanlı Bankas1, Comptoir d'Escompte ve AvusturyaOsmanlı Bankası'ndan alınan 1.600.000 İngiliz sterlini bedelindeki yeni kredi ile borçların bazı bölümleri kapatılmıştır. Kalan kredilerin kapatılması için artık resmi banka durumundaki Osmanlı Bankası aracılığıyla yeni bir genel borçlar tahvili çıkartılmıştır. 3.Tertip Genel Borçlar Düzenlemesi de denilen bu yeni kredinin kaydi bedeli 40.000 .000 sterlin veya 1.000.000.000 frank olarak hesaplanmıştır. Bu kredinin umumi borçlar olarak adlandırılmasının sebebi ise, karşılığında özel gelirin değil devletin genel vergi gelirlerinin bırakılmasıdır.

Kredinin faizi net $\% 5$ hesaplanmıştır. Osmanlı Bankası 375.000.000 frank tutarındaki tahvili $\% 43,5$ oranıyla satın almış ve 175.000 .000 franklık tahvili ise, devlete açılan hesaba karşın bırakmıştır. İstikrazın bırakılan kısmı 1875 yılı içinde muhtelif zamanlarda kullanılmıştır.

\section{Morotoryum- İflas}

Cari genel harcamalardan kaynaklanan bütçe dengesizliklerini karşılamak için hızlı bir kredi arayışına sürecine giren Osmanlı ekonomisi sonunda iflas bayrağını çekti. 1875 mali senesi için bütçe açığı 5.000.000 lirayı aştı. Aynı sene faiz ve anapara olarak 14.000.000 lira dış borç ödenmesi gerekmekteydi. Balkan'larda ayaklanmalarla ilgilenen ordu için çok hızlı 2.000.000 liraya ihtiyaç bulunmaktaydı. Bu duruma karşı1ık Mahmud Nedim Paşa(Sadrazam), tüm dünya borsalarında ağır tepkilere yol açacak hareketlere girişti. 6 Ekim 1875'te, Midhat Paşa'nın da dahil olduğu bir komisyon tarafından incelenip Sultan Abdülaziz'in onayladığı kararları aldıktan sonra bir kararname yayınlandı. Tüm gümrük gelirleri ve tütün, tuz, ağnam resmi ve Misır yıllık vergisi teminat olarak gösterilecek, bütçe açığı için 5.000.000'dan fazla borç almak imkansızd. Yeni koşullar oluşuyor ve alacaklılar için yeni bir yol oluşuyordu. Burada, diş borç taksit yarısı peşin ödenecek, yarısı 5 yıl vadeli ve $\% 5$ faizli yeni tahviller verilecektir bu durum da iflas anlamına geliyordu.

\section{SONUÇ}

6 Ekim 1875 tarihli bir kararnameyle, iflas resmen ilan edildi ve yabancı büyükelçiler gerekli açıklamaları aldılar. Belgeye göre, mevcut dış ve iç borçların borç ve faiz geri ödemeleri 5 yıl azaltılacaktır. 6 ay sonra dış borcun geri ödemesi tamamen durdurulacaktır. Beş yıl sonar ise pek çok uluslararası ödeme yapılmamış ve bu durum karmaşaya yol açmıştır. Avrupa ticaret sermayesiyle ittifak halindeki mültezimler arasındaki yenişememe durumu ve devletin, yabancı 
egemenliğindeki dinamik sektörü vergilendiremeyişi, borçlarını ödeyememesi anlamına geliyordu.

Yabancı alacaklıların temsilcileriyle yapılan uzun görüşmeler anlaşmaya yol açmış ve kararname 1881 'de ilan edilmiştir. İlan günü eski takvime göre 28 muharrem 1299'a rastladığından, "Muharrem Kararnamesi" olarak isimlendirilmiştir. Kararname ile 1854, 1855, 1871 ve 1877 borçlanmaları haricinde kalan tüm kredileri (faiz karşıllğı dış borçlanma); yani $1858,1860,1862,1863,1865,1869,1870,1873$ kredileri ile 1863 ve 1874 genel borçlarını içermektedir.

Kararname, içinde bulunan borçlardan ve faizlerinden bir kısım azaltmalar yapılmasını, bu duruma karşın ödemelerin garantili gelirlere bırakılmasını ve buna karşıllk bir teşkilat kurulmasını öngörüyordu. Bu teşkilata Düyun-u Umumiye adı verilmiştir.

İflastan sonrası ve Düyun-1 Umumiye'nin kurulması bu durumda bir farkl11ık yaratmad1; sadece bundan sonra devletin iktisadi hareketlerini ecnebiler denetliyordu ve Avrupa sermayesi, Osmanlı İmparatorluğu'ndan sağladığı büyük ayrıcalıklarla imparatorluğa girdi ve dünya iktisadıyla bütünleşme dönemini iç bölgelere ilerletti. Bu durum, ancak 1. Dünya Savaşı'ndan ve genel olarak Avrupa'dan tamamen iktisadi ve siyasal ayrışmadan sonra farklılaştı. Kapitülasyonların kalkmasından sonra, imparatorluk, milli sanayiyi koruyabildi ve destekledi, vergiyi kentsel alanlara yönelendirdi, aşarı ortadan kaldırdı ve böylece onları üreticilere dönüştürebildi.

\section{KAYNAKLAR}

Barkan, Ömer Lütfü, "The Price Revolution in the Sixteenth Century: A Tuming Point in Near Eastem Economic History", çeviren J. McCarthy, International Journal of Middle East Studies, 6 (1975).

Clay Christoper, Gold For The Sultan Western Bankers and Ottoman Finance 1856-1881: A Contribition to Ottoman and to International Financal History, I.B. Tauris Yayınlar1, New York, 2000, s.568-572

Deynekli, Emel; Kısa, Sedat; Açıklamalı - İçtihatlı Faiz Hukuku, 3. Bası, Ankara: Yetkin Basım Yayım ve Dağıtım A.Ş.Yayınları

İ. Hakkı Yeniay, Yeni Osmanlı Borçları Tarihi, İstanbul 1964.

Jari Eloranta and Mark Harrison, War and disintegration, 1914-1950 in The Cambridge Economic History of Modern Europe Volume 2, 1870 to the Present edited by Stephen Broadberry and Kevin H.O'Rourke, 2010.

Kalabak Ali Yasin, Osmanlı'nın Son Döneminin Sosyo Ekonomik Buhranları ve Mali Emperyalizm, Selçuk Üniversitesi İktisadi ve İdari Bilimler Fakültesi Sosyal ve Ekonomik Araştırmalar Dergisi, Nisan 2014 / Y11: 14 / Say1: 27

Kenan Bulutoğlu, Yüz Soruda Türkiye'de Yabancı Sermaye, İstanbul 1970.

Kıray Emine, Osmanlı'da Ekonomik Yapı ve Dış Borçlar, İletişim Yayınları, 2010,4.Bask1,

Kirkor Kömürcan, Türkiye İmparatorluk Devri Dış Borçlar Tarihçesi, İstanbul 1948. 
Tuncel Ahmet Kamil, Yıldırım Murat, 1854- 1874 Döneminde Osmanlı Devleti'nin Dış Borçlanması: Kaç Milyar Dolar Osmanlı Devleti'nin İflasına Neden Oldu? Trakya Üniversitesi Sosyal Bilimler Dergisi 1 Haziran 2014 Cilt 16 Say1 1

Yüksel Görmez,, "Banking in Turkey: History and Evolution, Bank of Greece, Eurosystem," Working paper, no. 83, 2008

Ziya Karamursal, Osmanlı Malî Tarihi Hakkında Tetkikler, Ankara 1940. 